ORIGINAL ARTICLE

\title{
Anticholinergic and Sedative Drug Burden and Functional Recovery after Cerebrovascular Accident: A Retrospective Descriptive Study
}

\author{
Yukari Ogawa, $\mathrm{PhD}{ }^{\text {a }}$ Futoshi Nibe, OTR, MS ${ }^{\mathrm{b}}$ Ryuichi Ogawa, $\mathrm{PhD}^{\mathrm{c}}$ and Masaharu Sakoh, MD, PhD ${ }^{\mathrm{b}}$
}

Objectives: Medications with anticholinergic or sedative effects induce impaired cognitive and physical performances. The aim of this study was to evaluate the associations of anticholinergic and sedative drug burden with recovery of physical function and activities of daily living in patients admitted to a Japanese rehabilitation hospital after cerebrovascular accidents. Methods: We retrospectively reviewed the medical records of patients aged 18 years or older who had undergone the inpatient rehabilitation program for cerebrovascular disease in Nerima Ken-ikukai Hospital. Patients who did not complete the rehabilitation program because of acute unexpected changes of physical or psychological condition or the need for surgical procedures were excluded. The primary outcome was recovery of activities of daily living as measured by the motor and cognitive subscores of the Functional Independence Measure. The secondary outcome was recovery of physical function as assessed by the $10-\mathrm{m}$ walk test and the Berg balance scale. Multiple Cox proportional hazard regression analyses were conducted to calculate hazard ratios with $95 \%$ confidence intervals for the outcome measures. Results: Of 122 patients included in the study, 81 $(66 \%)$ were exposed to anticholinergics and sedatives. Patients' age, body mass index, and average daily drug burden during hospitalization were independently associated with achieving the cutoff Functional Independence Measure-motor subscore. Patients' age and average daily drug burden during hospitalization were independently associated with achieving the Berg balance scale cut-off score. Conclusions: Our study of Japanese patients who were transferred from acute stroke care hospitals to a rehabilitation facility identified the drug burden of anticholinergics and sedatives as an independent factor associated with the time to recovery of activities of daily living and postural balance.

Key Words: activities of daily living; cholinergic antagonists; hypnotics and sedatives; postural balance; stroke

\section{INTRODUCTION}

Medications with anticholinergic or sedative effects induce impaired cognitive and physical performances. ${ }^{1-3)}$ A number of studies have found associations between medications and the risk of accidental falls in older patients. ${ }^{1,4)}$ The use of benzodiazepine receptor agonists is associated with in- creased risk of dementia and impaired physical performance measures. ${ }^{5,6)}$ Therefore, to minimize the risks of falls and fractures, the Beers criteria, ${ }^{7}$ ) the STOPP/START criteria, ${ }^{8)}$ and the Japanese Guidelines for Medical Treatment and its Safety in the Elderly ${ }^{9}$ ) recommend reassessment of appropriate use of some medications that can induce confusion, sedation, and hypotension in elderly patients. Moreover, because

Received: December 24, 2019, Accepted: May 7, 2020, Published online: May 16, 2020

${ }^{a}$ Department of Pharmacy, Faculty of Pharmacy, Musashino University, Tokyo, Japan

${ }^{\mathrm{b}}$ Convalescent Rehabilitation Center, Nerima Ken-ikukai Hospital, Tokyo, Japan

${ }^{c}$ Department of Pharmacotherapy, Meiji Pharmaceutical University, Tokyo, Japan

Correspondence: Yukari Ogawa, PhD, Department of Pharmacy, Faculty of Pharmacy, Musashino University, 1-1-20 Shinmachi Nishitokyo-shi, Tokyo 202-8585, Japan, E-mail: y_ogawa@musashino-u.ac.jp

Copyright (C) 2020 The Japanese Association of Rehabilitation Medicine

This is an open-access article distributed under the terms of the Creative Commons Attribution Non-Commercial No Derivatives (CC BY-NC-ND) 4.0 License. http://creativecommons.org/licenses/by-nc-nd/4.0/ 
the risk of falls is increased by initiation and dose escalation of benzodiazepines not only in the elderly but also in middleaged inpatients, ${ }^{10)}$ the middle-aged population shares the same risk of those medications as older persons. According to a meta-analysis, ${ }^{11)}$ the use not only of benzodiazepines but also of sedative hypnotics, antipsychotics, and antidepressants increases the risk of falls.

Anticholinergic agents act on the muscarinic receptors in the central and peripheral nervous systems and inhibit acetylcholine-mediated responses by binding to these receptors. Typical and central side effects are dry mouth, nausea, vomiting, dizziness, weakness, and mental confusion. ${ }^{12)}$ A previous study described an association between worse physical performance and cumulative exposure to anticholinergic medication. ${ }^{12}$ Medications with anticholinergic and sedative effects are often taken concurrently in clinical practice. According to a previous study, ${ }^{13)} 30 \%$ of inpatients in a Japanese rehabilitation hospital were taking psychotropic agents, including concurrent administrations of anticholinergic agents such as medications for overactive bladder and sedative drugs such as benzodiazepine receptor agonists.

The drug burden index (DBI) is a pharmacological risk assessment tool that calculates exposure to both anticholinergic and sedative agents. ${ }^{14)}$ The index is based on the principles of cumulative exposure and dose response. The DBI is the sum of scores for prescribed medications with anticholinergic and sedative effects for each patient. Previous studies have reported that increases in the DBI score are associated with significant functional impairment in older patients. ${ }^{15-17)}$ Additionally, Hilmer et al. ${ }^{18)}$ showed that both DBI and the cumulative exposure, calculated as the area under the curve for drug burden, were associated with lower objective physical function over 5 years in community-dwelling older people.

In Japan, convalescent rehabilitation wards, called Kaifu$k u$ - $k i$ rehabilitation wards, were established by the national insurance system in 2000. Patients who are admitted to a convalescent rehabilitation ward can receive early and intensive rehabilitation. The purpose of convalescent-phase inpatient rehabilitation programs for patients who have had cerebrovascular accidents is to help them to recover physical functions and activities of daily living (ADL) and to re-establish an independent life. Currently, the maximum length of stay covered by medical insurance is 150 days for stroke and 180 days for stroke with other neurological diseases with severe disability and cognitive impairment. Discharge is considered when a patient reaches a plateau of ADL, as evaluated by outcome measures such as the Functional Independence Measure (FIM) comprising the FIM-motor subscore (FIM-
M) and the FIM-cognitive subscore (FIM-C). ${ }^{19)}$

To the best of our knowledge, information is scarce on the association between medications with anticholinergic or sedative effects and the recovery of physical functions, including walking ability and ADL. Therefore, the influence of these drugs on rehabilitation outcomes is an unresolved issue in the field of rehabilitation. Consequently, the aim of this study was to evaluate the associations of the anticholinergic and sedative drug burden with the recovery of physical function and ADL after cerebrovascular diseases in a rehabilitation hospital in Japan.

\section{METHODS}

\section{Study Design and Patients}

The study design was that of a retrospective descriptive study. We reviewed the medical records of patients who were admitted to Nerima Ken-ikukai Hospital, a convalescent rehabilitation center with a convalescent ward, between May 2017 and March 2018. Eligible patients were 18 years of age or older and had undergone the rehabilitation program for cerebrovascular disease. We excluded those patients who did not complete the rehabilitation program in our facility for the following reasons: transfer to another hospital because of acute unexpected changes of physical or psychological condition or the need for surgical procedures (details are listed in Fig. 1), and difficulties of follow-up, for example, because the patient moved house. The following covariates were retrieved from medical charts: age, sex, type of cerebrovascular disease, height, body weight, length of stay, complications, the presence of higher brain dysfunction, and the time of onset of cerebrovascular disease. The study protocol was approved by the Ethics Committee of Nerima Ken-ikukai Hospital (approval number: Rin-1). The study was conducted in accordance with the Declaration of Helsinki.

\section{Rehabilitation Routine}

Therapists consult with the attending physician who determines the frequency or duration of rehabilitation according to the patient's background (e.g., age, physical condition, and comorbidities). The main rehabilitation programs were (1) range-of-motion exercises, standing balance training, transfer training, and walking training by physical therapists; (2) ADL training, upper limb rehabilitation, training for higher brain function, and mental practice for brain activation by occupational therapists; and (3) aphasia therapy, articulation therapy, dysphagia rehabilitation, and training for higher brain function by speech therapists. The standard rehabilita- 
Patients admitted between May 2017 and March 2018

$(\mathrm{n}=325)$

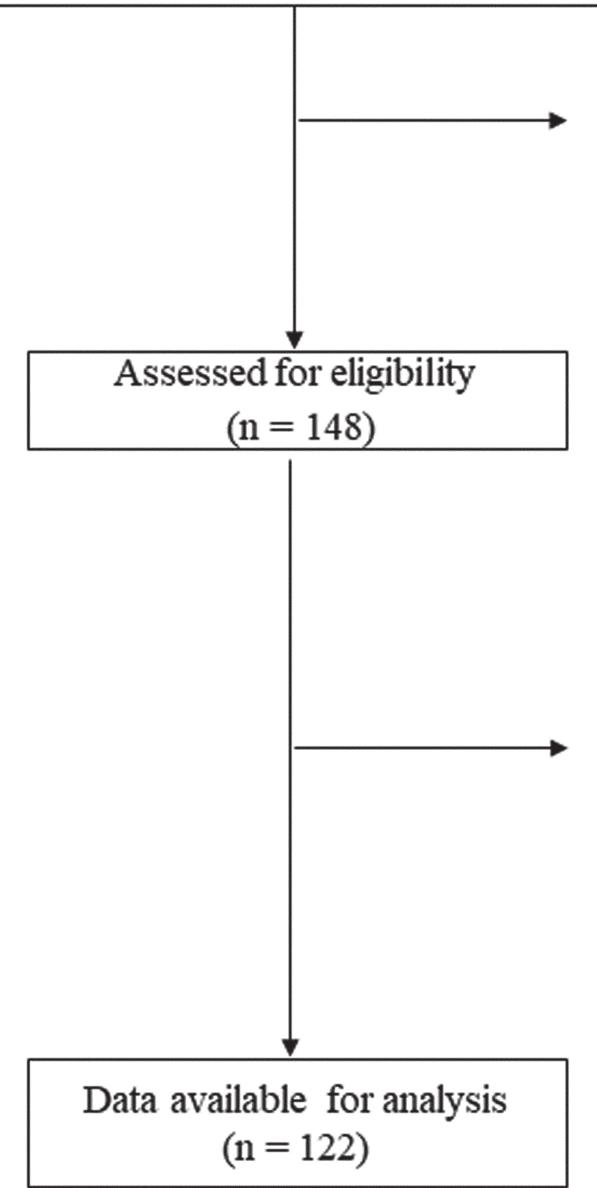

Excluded (total $=177$ )

- Age below 18 years $(n=2)$

- Musculoskeletal rehabilitation programs $(n=152)$

- Disuse syndrome rehabilitation programs $(n=23)$

Excluded (total $=26$ )

- Percutaneous endoscopic gastrostomy $(n=6)$

- Unexpected change of physical condition $(n=16)$

- pneumonia $(n=4)$, sepsis $(n=1)$

- worsen heart failure $(\mathrm{n}=2)$

- recurrence stroke $(\mathrm{n}=2)$

- others $(\mathrm{n}=7)$

- Unexpected change of psychological condition $(n=2)$

- Unable to follow-up due to geographical matters $(n=2)$

Fig. 1. STROBE flow chart of the study cohort.

tion program in our hospital includes three to six sessions per day of physical therapy, two to four sessions per day of occupational therapy, and zero to three sessions per day of speech therapy (a total of nine sessions per day); each session lasts $20 \mathrm{~min}$.

\section{Outcomes}

The primary outcome was recovery of ADL from baseline (at admission), as measured by FIM-M and FIM-C. FIM is a composite scale consisting of 18 items that assess 6 areas of function: self-care, sphincter control, mobility, locomotion, communication, and social cognition. FIM can be subdivided into FIM-M and FIM-C, which assess the physical domain and cognitive domain, respectively. The scores ranged from 13 to 91 points for FIM-M and from 5 to 35 points for FIMC. We preferred to analyze FIM-M and FIM-C to evaluate physical and cognitive function separately, rather than using the combined FIM score. We used FIM version 3.1. ${ }^{20)}$ The secondary outcome was recovery of physical function from baseline measured by the $10-\mathrm{m}$ walk test (10MWT) and the Berg balance scale (BBS). The 10MWT is widely used to assess gait speed because it is safe, simple to administer, and psychometrically well established. We applied a comfortable walking speed during the 10MWT. ${ }^{21,22)}$ Physical therapists performed 10MWT twice and calculated the average time. The BBS provides a quantitative assessment of balance. This scale is composed of 14 items that require patients to maintain various physical positions and to complete movement tasks of varying degrees of difficulty. ${ }^{23)}$ The maximum score is 56 points.

We evaluated the outcome measures (FIM-M, FIM-C, 10MWT, and BBS) at admission; on hospital days 30, 60, and 90; and at discharge. We calculated the time to achieve the cut-off point for recovery for each outcome measure. 
Based on previous studies, the definition of "recovery" was set by discussions among medical doctors, physical therapists, occupational therapists, and pharmacists. ${ }^{24-26)}$ We used the following cut-off values to define "recovery" of ADL and physical function: (1) 58 points for FIM-M, (2) 24 points for FIM-C, (3) $25 \mathrm{~s}$ for 10MWT, and (4) 45 points for BBS. According to a previous study, ${ }^{24)}$ the cut-off values of 58 and 24 points for FIM-M and FIM-C, respectively, are the borderline ADL measures for home discharge of post-stroke patients. The cut-off score of $25 \mathrm{~s}$ for 10MWT is reportedly the cut-off value for a least-limited community walker who can independently negotiate both local stores and uncrowded shopping centers. ${ }^{25}$ ) The cut-off score of 45 points for BBS has been reported as the cut-off value between individuals who are safe to ambulate independently and those who require assessment concerning their need for assistive devices or supervision. ${ }^{26)}$

\section{Medication Exposure}

We hypothesized that anticholinergic and sedative drugs are potential risk factors that delay the recovery of ADL and physical functions. Medications with anticholinergic or sedative effects included in this study were antidepressants, antipsychotics, antihistamines, dopaminergics, opioid receptor agonists, hypnotics (including benzodiazepine receptor agonists), anticonvulsants, muscarinic antagonists for overactive bladder, codeine, disopyramide, furosemide, isosorbide, loperamide, nifedipine, theophylline, and warfarin. Medications with anticholinergic effects were identified according to the anticholinergic rank scale, ${ }^{27)}$ the anticholinergic cognitive burden scale, ${ }^{28)}$ and the anticholinergic drug scale. ${ }^{29)}$ Exposure to anticholinergic and sedative medications was quantified using total drug burden (TDB). TDB depends not only on the number of prescribed drugs but also on the daily dosage. TDB was calculated for each patient according to the following equation ${ }^{14)}$ :

$$
\mathrm{TDB}=\mathrm{DBI}_{\mathrm{AC}}+\mathrm{DBI}_{\mathrm{S}}
$$

where $\mathrm{DBI}_{\mathrm{AC}}$ and $\mathrm{DBI}_{\mathrm{S}}$ represent the standardized drug burden from anticholinergic and sedative drugs, respectively. DBI was calculated using the following equation:

$$
\mathrm{DBI}=\sum \frac{\mathrm{D}_{\text {actual }}}{\mathrm{D}_{\text {minimum }}+\mathrm{D}_{\text {actual }}}
$$

where $\mathrm{D}_{\text {actual }}$ is the daily dose taken by the patient and $\mathrm{D}_{\text {minimum }}$ is the recommended minimum daily dose approved by Ministry of Health, Labour and Welfare. If a patient was administered the minimum approved daily dose of a certain drug, the DBI of the drug would be 0.5 . Topical medications without significant systemic effects (e.g., ointments and eye drops) were excluded from analysis. However, we included isosorbide tape because, although it is topical, it is expected to produce systemic effects.

TDB was calculated at admission, every 30 days thereafter, and at discharge. Cumulative exposure of the drugs of interest over the entire period of hospitalization (AUCDB) was calculated as the area under the curve for TDB by applying the trapezoidal rule ${ }^{18)}$ because patients who are admitted to rehabilitation hospitals in Japan are in the subacute stage and their prescriptions are modified according to their medical conditions. For example, we would calculate AUCDB for a patient whose length of stay was 50 days as:

$$
\begin{aligned}
\mathrm{AUCDB} & =\frac{\left(\mathrm{TDB}_{1}+\mathrm{TDB}_{30}\right) \times 30 \text { days }}{2} \\
& +\frac{\left(\mathrm{TDB}_{30}+\mathrm{TDB}_{50}\right) \times 20 \text { days }}{2}
\end{aligned}
$$

We also calculated the average daily drug burden during hospitalization for each patient because longer hospital stays usually result in a greater AUCDB. The average daily drug burden was calculated using the following equation:

average daily drug burden

$$
=\frac{\text { AUCDB }}{\text { length of stay }(\text { days })}
$$

Patients were classified into three groups according to the calculated average daily drug burden as follows: (1) no drug burden throughout the hospital stay (zero drug burden group), (2) average daily drug burden between 0.01 and 0.49 (low drug burden group), and (3) average daily drug burden $>0.49$ (high burden group). We allocated patients who took medications with anticholinergic or sedative effects during hospitalization into two groups. The cut-off value of 0.49 was the median value for all patients, excluding patients in the zero drug burden group.

\section{Statistical Analysis}

Data are presented as medians with first and third quartiles. The Kruskal-Wallis test and the chi-squared test were used to compare numerical and categorical data, respectively, among groups (zero, low, and high drug burden groups). Univariate and multiple Cox proportional hazard regression analyses were conducted to calculate hazard ratios (HR) and 95\% con- 
fidence intervals (CI) for achievement of the cut-off values of the outcome measures. In this study, higher HR values mean an association with longer times to achieve the cut-off value of outcome measures. We incorporated age, sex, body mass index (BMI), the presence of higher brain dysfunction, and the average daily drug burden as covariates into the multiple Cox proportional hazard regression analysis. In addition to the variables specified above, other variables with $\mathrm{P}$ values below 0.10 in the univariate analyses were also included as potential covariates in the multivariate analysis. We examined the existence of multicollinearity between factors using Pearson's or Spearman's rank-correlation coefficients. When there was significant multicollinearity between variables, we selected one of them based on its clinical relevance. We performed subgroup analyses by stratifying age $(\leq 64,65-80$, $\geq 81$ years $)$ and BMI $(\leq 18.4,18.5-24.9, \geq 25)$ to evaluate the interactions of these factors with the outcome measures. Statistical significance was defined by a two-sided alpha level of 0.05. A sample size calculation for the Cox proportional hazard regression model with nonbinary covariates ${ }^{30}$ ) with alpha and beta errors of 0.05 and 0.2 , respectively, indicated that a total of 80 patients who achieved the primary outcome were required to detect a daily drug burden with a HR of 0.95 per 0.1 increase in the daily drug burden. All statistical analyses were performed using Stata 15 (College Station, TX, USA).

\section{RESULTS}

\section{Patient Characteristics}

In total, 122 patients were included in the analysis (Fig. 1). The clinical characteristics of the study population are shown in Table 1. Eighty-one patients (59\%) took medications that contributed to the drug burden during hospitalization. Benzodiazepine receptor agonists were the most frequently prescribed class contributing to the drug burden in this population [total: 43 patients (35\%); low drug burden group: 15 patients (33\%), high drug burden group: 28 patients $(80 \%)]$. The median time from the onset of cerebrovascular disease to admission was 37 days (zero drug burden group: 35 days, low drug burden group: 37 days, high drug burden group: 41 days). The values of the outcome measures at admission and discharge are shown in Table 2. The median TDB increased during hospitalization from 0.00 to 0.50 in the low drug burden group and from 0.50 to 1.00 in the high drug burden group (Table 3). The frequencies of anticholinergic and sedative medications used in this study population are shown in Table 4. The number of patients administered antipsychotics, benzodiazepine receptor agonists, anticonvulsants, and others (furosemide, isosorbide, loperamide, nifedipine, theophylline, and warfarin) were higher in the high drug burden group than in the low drug burden group.

\section{FIM-Motor Subscore}

Table 5 shows the results of multiple Cox proportional hazard regression analysis for primary outcomes. Age [HR 0.985 (95\% CI 0.972-0.999), $\mathrm{P}=0.033$ ], BMI [HR 1.066 (1.011-1.133), $\mathrm{P}=0.045]$, and the average daily drug burden [HR 0.935 (0.889-0.983), $\mathrm{P}=0.008$ ] were independent variables associated with the time to achieve the FIM-M cut-off value. Thirty-five patients $(85 \%)$ in the zero drug burden group, 33 patients $(72 \%)$ in the low drug burden group, and 21 patients $(60 \%)$ in the high drug burden group achieved the FIM-M cut-off score (58 points) during hospitalization.

\section{FIM-Cognitive Subscore}

Multiple Cox proportional hazard regression analysis also indicated that BMI [HR 1.073 (1.011-1.138), $\mathrm{P}=0.020$ ] was an independent variable associated with the time to achieve the FIM-C cut-off value (Table 5). Thirty-four patients (83\%) in the zero drug burden group, 32 patients $(70 \%)$ in the low drug burden group, and 20 patients (57\%) in the high drug burden group achieved the FIM-C cut-off score ( 24 points) during hospitalization.

\section{Ten-meter Walk Test}

Twenty-one patients were unable to undergo or complete the 10MWT during hospitalization because of impaired walking ability, difficulty with understanding, or orthostatic hypertension. Thirty-six patients $(88 \%)$ in the zero drug burden group, 32 patients $(70 \%)$ in the low drug burden group, and 18 patients (51\%) in the high drug burden group achieved the 10MWT cut-off time (25 s) during hospitalization. Table 6 shows the results of multiple Cox proportional hazard regression analysis.

\section{Berg Balance Scale}

Table 6 shows the results of multiple Cox proportional hazard regression analysis. Age [HR 0.980 (0.966-0.994), $\mathrm{P}=0.005$ ] and the average daily drug burden [HR 0.924 (0.872-0.979), $\mathrm{P}=0.008]$ were independent variables associated with the time to achieve the BBS cut-off value (Table 6). One patient did not undergo BBS measurement because of being discharged within 30 days (i.e., before the first measurement after admission). Thirty-one patients (76\%) in the zero drug burden group, 25 patients (54\%) in the low drug 
Table 1. Clinical characteristics of the study population

\begin{tabular}{|c|c|c|c|c|c|}
\hline & \multirow[b]{2}{*}{$\begin{array}{l}\text { Overall } \\
(\mathrm{n}=122)\end{array}$} & \multirow[b]{2}{*}{$\begin{array}{c}\text { Zero DB } \\
(\mathrm{n}=41)\end{array}$} & \multicolumn{2}{|c|}{ Average daily drug burden $\geq 0.01^{*}$} & \multirow[b]{2}{*}{ P-value** } \\
\hline & & & $\begin{array}{c}\text { Low DB } \\
(\mathrm{n}=46)\end{array}$ & $\begin{array}{l}\text { High DB } \\
(\mathrm{n}=35)\end{array}$ & \\
\hline Age, years & $76[56,83]$ & $73[54,82]$ & $75[61,82]$ & $79[57,83]$ & 0.962 \\
\hline$\leq 64, \mathrm{n}(\%)$ & $39(32)$ & $14(34)$ & $14(30)$ & $11(31)$ & 0.931 \\
\hline $65-80, \mathrm{n}(\%)$ & $39(32)$ & $13(32)$ & $16(35)$ & $10(29)$ & 0.838 \\
\hline$\geq 81, \mathrm{n}(\%)$ & $44(36)$ & $14(34)$ & $16(35)$ & $14(40)$ & 0.846 \\
\hline Female, n (\%) & $48(39)$ & $12(29)$ & $19(41)$ & $17(49)$ & 0.216 \\
\hline Height, $\mathrm{cm}$ & $161[153,167]$ & $163[155,170]$ & $160[153,166]$ & $161[154,166]$ & 0.421 \\
\hline Body weight, kg & $54[49,62]$ & $56[50,67]$ & $53[48,58]$ & $53[46,58]$ & 0.102 \\
\hline BMI, $\mathrm{kg} / \mathrm{m}^{2}$ & $20.8[19.2,23.2]$ & $21.3[19.3,22.4]$ & $20.7[19.3,22.4]$ & $20.6[18.5,23.0]$ & 0.128 \\
\hline $\mathrm{BMI}<18.5, \mathrm{n}(\%)$ & $22(18)$ & $4(10)$ & $9(20)$ & $9(26)$ & 0.185 \\
\hline $18.5 \leq \mathrm{BMI} \leq 24.9, \mathrm{n}(\%)$ & $85(70)$ & $28(68)$ & $32(70)$ & $25(71)$ & 0.957 \\
\hline $\mathrm{BMI} \geq 25, \mathrm{n}(\%)$ & $15(12)$ & $9(22)$ & $5(11)$ & $1(3)$ & 0.038 \\
\hline Higher brain dysfunction, n (\%) & $85(70)$ & $26(63)$ & $33(72)$ & $26(74)$ & 0.547 \\
\hline $\begin{array}{l}\text { Time from onset of cerebrovascular } \\
\text { accident to admission, days }\end{array}$ & $37[28,45]$ & $35[27,42]$ & $37[29,46]$ & $41[28,54]$ & 0.145 \\
\hline \multicolumn{6}{|l|}{ Type of cerebrovascular disease } \\
\hline Cerebral infarction, $\mathrm{n}(\%)$ & $53(43)$ & $18(44)$ & $20(43)$ & $15(43)$ & 0.996 \\
\hline Intracerebral hemorrhage, $\mathrm{n}(\%)$ & $24(20)$ & $11(27)$ & $7(15)$ & $6(17)$ & 0.359 \\
\hline Subarachnoid hemorrhage, n (\%) & $11(9)$ & $2(5)$ & $7(15)$ & $2(6)$ & 0.176 \\
\hline Others***, n (\%) & $34(28)$ & $10(24)$ & $12(26)$ & $12(34)$ & 0.596 \\
\hline Atrial fibrillation, n (\%) & $20(16)$ & $4(10)$ & $8(17)$ & $8(23)$ & 0.298 \\
\hline Coronary heart disease, $\mathrm{n}(\%)$ & $19(16)$ & $5(12)$ & $10(22)$ & $4(11)$ & 0.342 \\
\hline Dementia, n (\%) & $10(8)$ & $3(7)$ & $4(9)$ & $3(9)$ & 0.969 \\
\hline Diabetes mellitus, n (\%) & $20(16)$ & $7(17)$ & $8(17)$ & $5(14)$ & 0.923 \\
\hline Epilepsy, n (\%) & $9(7)$ & $0(0)$ & $2(4)$ & $7(20)$ & 0.002 \\
\hline Heart failure, n (\%) & $8(7)$ & $3(7)$ & $2(4)$ & $3(9)$ & 0.727 \\
\hline Hypertension, n (\%) & $81(66)$ & $28(68)$ & $33(72)$ & $20(57)$ & 0.368 \\
\hline Parkinson's disease, n (\%) & $3(2)$ & $1(2)$ & $1(2)$ & $1(3)$ & 0.981 \\
\hline
\end{tabular}

Data are presented as median [first quartile, third quartile] or number (percent).

* Low DB: average daily drug burden $0.01-0.49$, High DB: average daily drug burden $>0.49$.

** Kruskal-Wallis test or chi-squared test, comparing three groups.

*** Head trauma, traumatic subarachnoid hemorrhage, and brain tumor.

BMI, body mass index; DB, drug burden.

burden group, and 15 patients (43\%) in the high drug burden group achieved the BBS cut-off score (45 points) during hospitalization.

\section{Subgroup Analyses}

Subgroup analyses showed that the associations of independent variables (age, BMI, and average daily drug burden) with outcome measures (FIM-M, FIM-C, and BBS) were consistent across different age groups and BMI groups (Fig. 2).

\section{DISCUSSION}

We demonstrated that a higher average daily drug burden was associated with delayed recovery of BBS and FIM-M in patients admitted to a rehabilitation hospital after cerebrovascular accidents. Patients in the convalescent ward are regularly monitored (usually monthly) for FIM-M and FIM$\mathrm{C}$ to assess ADL in clinical practice. Our study revealed that, in addition to age and BMI, the average daily drug burden was independently associated with the time to achieve the FIM-M cut-off value. Higher DBI values were reportedly 
Table 2. Outcome measures in the study

\begin{tabular}{|c|c|c|c|c|c|}
\hline \multirow{2}{*}{ Outcome measure } & \multirow{2}{*}{$\begin{array}{l}\text { Overall } \\
(n=122)\end{array}$} & \multirow{2}{*}{$\begin{array}{c}\text { Zero DB } \\
(\mathrm{n}=41)\end{array}$} & \multicolumn{2}{|c|}{ Average daily drug burden $\geq 0.01 *$} & \multirow{2}{*}{ P-value** } \\
\hline & & & Low DB $(n=46)$ & High DB $(n=35)$ & \\
\hline \multicolumn{6}{|l|}{ 10MWT, s } \\
\hline Admission & $12.0[8.5,18.6]$ & $10.3[8.0,18.1]$ & $11.9[9.6,17.5]$ & $14.4[10.5,23.9]$ & 0.282 \\
\hline Discharge & $10.3[7.4,17.6]$ & $8.8[6.7,16.4]$ & $10.9[8.5,14.7]$ & $10.5[7.5,27.6]$ & 0.170 \\
\hline \multicolumn{6}{|l|}{ BBS, points } \\
\hline Admission & $30[4,48]$ & $39[7,51]$ & $31[3,44]$ & $12[3,40]$ & 0.048 \\
\hline Discharge & $48[23,54]$ & $53[44,55]$ & $47[25,53]$ & $41[15,53]$ & 0.015 \\
\hline \multicolumn{6}{|l|}{ FIM-M, points } \\
\hline Admission & $47[23,65]$ & $53[29,70]$ & $48[23,65]$ & $31[22,52]$ & 0.031 \\
\hline Discharge & $83[57,90]$ & $87[76,90]$ & $82[55,90]$ & $77[41,87]$ & 0.039 \\
\hline \multicolumn{6}{|l|}{ FIM-C, points } \\
\hline Admission & $22[12,28]$ & $23[18,30]$ & $23[10,29]$ & $18[9,23]$ & 0.034 \\
\hline Discharge & $29[18,35]$ & $31[26,35]$ & $30[13,35]$ & $27[16,34]$ & 0.159 \\
\hline
\end{tabular}

Data are presented as median [first quartile, third quartile].

* Low DB: average daily drug burden $0.01-0.49$, High DB: average daily drug burden $>0.49$.

** Kruskal-Wallis test, comparing three groups.

Table 3. Drug burden parameters and length of hospital stay

\begin{tabular}{|c|c|c|c|c|c|}
\hline & \multirow{2}{*}{$\begin{array}{l}\text { Overall } \\
(n=122)\end{array}$} & \multirow{2}{*}{$\begin{array}{l}\text { Zero DB } \\
(\mathrm{n}=41)\end{array}$} & \multicolumn{2}{|c|}{ Average daily drug burden $\geq 0.01^{*}$} & \multirow{2}{*}{ P-value** } \\
\hline & & & Low DB $(n=46)$ & High DB $(n=35)$ & \\
\hline $\begin{array}{l}\text { Anticholinergic and sedative } \\
\text { drugs, n/a patient }\end{array}$ & $1[0,2]$ & 0 & $1[1,1]$ & $3[2,4]$ & $<0.001$ \\
\hline TDB at admission & $0.00[0.00,0.50]$ & 0 & $0.00[0.00,0.50]$ & $0.50[0.41,0.92]$ & $<0.001$ \\
\hline TDB at 30 days & $0.20[0.00,0.50]$ & 0 & $0.33[0.00,0.50]$ & $0.83[0.50,1.50]$ & $<0.001$ \\
\hline TDB at 60 days & $0.50[0.00,0.70]$ & 0 & $0.50[0.24,0.50]$ & $1.00[0.68,1.38]$ & $<0.001$ \\
\hline TDB at 90 days & $0.42[0.00,1.00]$ & 0 & $0.33[0.15,0.50]$ & $1.00[0.67,1.55]$ & $<0.001$ \\
\hline TDB at discharge & $0.38[0.00,0.67]$ & 0 & $0.50[0.27,0.50]$ & $1.00[0.67,1.58]$ & $<0.001$ \\
\hline AUCDB & $17.50[0.00,53.08]$ & 0 & $19.72[9.33,36.25]$ & $91.83[52.83,145.01]$ & $<0.001$ \\
\hline Average daily drug burden & $0.32[0.00,0.57]$ & 0 & $0.33[0.24,0.46]$ & $0.77[0.66,1.39]$ & $<0.001$ \\
\hline Length of stay, days & $87[49,125]$ & $77[45,112]$ & $84[49,108]$ & $107[63,146]$ & 0.172 \\
\hline
\end{tabular}

Data are presented as median [first quartile, third quartile].

* Low DB: average daily drug burden 0.01-0.49, High DB: average daily drug burden $>0.49$.

** Kruskal-Wallis test, comparing three groups.

associated with ADL disability after 3-year follow-up in Japanese elderly persons aged 85 years or older. ${ }^{31)}$ Although our study population did not exclusively consist of elderly patients and the follow-up duration was less than 1 year, our results showed the same tendency as that identified in the previous report. ${ }^{31)}$ However, it remains unclear which items in FIM-M are most influenced by the average daily drug burden, age, and BMI, because we did not retrieve those details in this study. Our results also indicated that higher BMI was associated with faster improvement in FIM-M and FIM-C. Previous studies have reported that sarcopenia weakened physical function, ${ }^{32)}$ whereas obesity had a negative effect on the recovery of physical function. ${ }^{33)}$ There was only one patient with a BMI greater than $30 \mathrm{~kg} / \mathrm{m}^{2}$ in this study. Therefore, in our study population, we speculated that BMI was an indicator of nutritional status, not obesity.

Several recent long-term studies have addressed the association between the use of anticholinergic or sedative drugs and cognitive impairment. ${ }^{2,34,35)}$ However, we found no significant association between the average daily drug burden and FIM-C in patients of our convalescent ward. Patients transferred from acute stroke care facilities to convalescent 
Table 4. The frequencies of use of medications contributing to the drug burden index

\begin{tabular}{|c|c|c|c|c|c|}
\hline \multirow[b]{2}{*}{ Drug class* } & \multirow{2}{*}{$\begin{array}{l}\text { Overall } \\
(n=122)\end{array}$} & \multirow[b]{2}{*}{$\begin{array}{c}\text { Zero DB } \\
(n=41)\end{array}$} & \multicolumn{2}{|c|}{ Average daily drug burden $\geq 0.01 * *$} & \multirow[b]{2}{*}{ P-value*** } \\
\hline & & & $\begin{array}{c}\text { Low DB } \\
(\mathrm{n}=46)\end{array}$ & $\begin{array}{l}\text { High DB } \\
(n=35)\end{array}$ & \\
\hline Antidepressants, n (\%) & $15(12)$ & $0(0)$ & $6(13)$ & $9(26)$ & 0.146 \\
\hline Antipsychotics, n (\%) & $20(16)$ & $0(0)$ & $5(11)$ & $15(43)$ & 0.001 \\
\hline Antihistamines, n (\%) & $15(12)$ & $0(0)$ & $9(20)$ & $6(17)$ & 0.781 \\
\hline Dopaminergic, n (\%) & $9(7)$ & $0(0)$ & $4(9)$ & $5(14)$ & 0.663 \\
\hline Opioid receptor agonists, $\mathrm{n}(\%)$ & $2(2)$ & $0(0)$ & $0(0)$ & $2(6)$ & - \\
\hline Benzodiazepine receptor agonists, $\mathrm{n}(\%)$ & $46(38)$ & $0(0)$ & $15(33)$ & $28(80)$ & $<0.001$ \\
\hline Suvorexant or ramelteon, $\mathrm{n}(\%)$ & $8(7)$ & $0(0)$ & $3(7)$ & $5(14)$ & 0.246 \\
\hline Anticonvulsants, n (\%) & $26(21)$ & $0(0)$ & $6(13)$ & $20(57)$ & $<0.001$ \\
\hline Muscarinic antagonists for bladder, n (\%) & $11(9)$ & $0(0)$ & $6(13)$ & $5(14)$ & 0.872 \\
\hline Others $* * * *, n(\%)$ & $18(15)$ & $0(0)$ & $5(11)$ & $13(37)$ & 0.012 \\
\hline
\end{tabular}

*Patients who took the drug at least once during hospitalization were counted, even if the drug was discontinued before discharge.

** Low DB: average daily drug burden $0.01-0.49$, High DB: average daily drug burden $>0.49$.

$* * *$ Chi-squared test (Low DB vs High DB).

$* * * *$ Furosemide, isosorbide, loperamide, nifedipine, theophylline, and warfarin.

Table 5. Results of Cox proportional hazard regression analysis for primary outcomes

\begin{tabular}{lcccc}
\hline Outcome & \multicolumn{1}{c}{ Univariate } & & Multivariate \\
variables & HR $(95 \%$ CI $)$ & P-value & Adjusted HR $(95 \%$ CI $)$ & P-value \\
\hline Time to achieve FIM-M cutoff & & & & \\
Age, per year & $0.988(0.977,0.999)$ & 0.039 & $0.985(0.972,0.999)$ & 0.033 \\
Female & $0.761(0.493,1.176)$ & 0.219 & $0.851(0.540,1.342)$ & 0.487 \\
BMI, per kg/m ${ }^{2}$ & $1.074(1.005,1.148)$ & 0.036 & $1.066(1.011,1.133)$ & 0.045 \\
Presence of higher brain dysfunction & $0.680(0.437,1.059)$ & 0.088 & $0.724(0.457,1.148)$ & 0.170 \\
Average daily drug burden, per 0.1 & $0.948(0.904,0.995)$ & 0.030 & $0.935(0.889,0.983)$ & 0.008 \\
Presence of cerebral infarction & $0.608(0.394,0.938)$ & 0.024 & $0.913(0.524,1.592)$ & 0.749 \\
Presence of other cerebrovascular disease* & $1.756(1.124,2.742)$ & 0.013 & $1.665(0.958,2.893)$ & 0.071 \\
\hline Time to achieve FIM-C cutoff & & & & \\
Age, per year & $0.989(0.977,1.001)$ & 0.080 & $0.988(0.975,1.002)$ & 0.085 \\
Female & $0.968(0.626,1.496)$ & 0.884 & $1.061(0.677,1.664)$ & 0.796 \\
BMI, per kg/m ${ }^{2}$ & $1.082(1.017,1.150)$ & 0.012 & $1.073(1.011,1.138)$ & 0.020 \\
Presence of higher brain dysfunction & $0.636(0.405,0.997)$ & 0.048 & $0.729(0.452,1.177)$ & 0.196 \\
Average daily drug burden, per 0.1 & $0.964(0.919,1.011)$ & 0.127 & $0.962(0.917,1.009)$ & 0.115 \\
Presence of other cerebrovascular disease* & $1.486(0.937,2.358)$ & 0.093 & $1.327(0.820,2.147)$ & 0.250 \\
Presence of hypertension & $0.683(0.440,1.058)$ & 0.088 & $0.799(0.504,1.267)$ & 0.341 \\
\hline
\end{tabular}

* Head trauma, traumatic subarachnoid hemorrhage, brain tumor.

CI, confidence interval; HR, hazard ratio

hospitals are in the sub-acute stage of cerebrovascular accidents, and their higher brain function is in the process of recovery. Because early treatment with selective serotonin reuptake inhibitors could be beneficial for the recovery of FIM in patients with post-stroke depression, ${ }^{36,37)}$ the ef- fectiveness of anticholinergic and sedative drugs might outweigh the risk of any negative effects on cognitive function during this period.

The 10MWT and BBS are often used to assess gait speed and balance, respectively. We found that, in addition to age, 
Table 6. Results of Cox proportional hazard regression analysis for secondary outcomes

\begin{tabular}{|c|c|c|c|c|}
\hline \multirow{2}{*}{$\begin{array}{l}\text { Outcome } \\
\text { variables }\end{array}$} & \multicolumn{2}{|c|}{ Univariate } & \multicolumn{2}{|l|}{ Multivariate } \\
\hline & $\operatorname{HR}(95 \% \mathrm{CI})$ & P-value & Adjusted HR (95\% CI) & P-value \\
\hline \multicolumn{5}{|l|}{ Time to achieve $10 \mathrm{MWT}$ cutoff } \\
\hline Age, per year & $0.998(0.986,1.011)$ & 0.815 & $0.996(0.982,1.010)$ & 0.591 \\
\hline Female & $0.971(0.623,1.512)$ & 0.895 & $1.013(0.663,1.621)$ & 0.958 \\
\hline BMI, per $\mathrm{kg} / \mathrm{m}^{2}$ & $1.022(0.960,1.088)$ & 0.501 & $1.017(0.953,1.084)$ & 0.617 \\
\hline Presence of higher brain dysfunction & $0.723(0.461,1.134)$ & 0.157 & $0.757(0.477,1.203)$ & 0.239 \\
\hline Average daily drug burden, per 0.1 & $0.965(0.921,1.011)$ & 0.138 & $0.967(0.922,1.016)$ & 0.181 \\
\hline \multicolumn{5}{|l|}{ Time to achieve BBS cutoff } \\
\hline Age, per year & $0.987(0.975,0.999)$ & 0.042 & $0.980(0.966,0.994)$ & 0.005 \\
\hline Female & $0.839(0.519,1.357)$ & 0.475 & $0.945(0.570,1.565)$ & 0.825 \\
\hline BMI, per $\mathrm{kg} / \mathrm{m}^{2}$ & $1.059(0.986,1.138)$ & 0.117 & $1.049(0.978,1.124)$ & 0.179 \\
\hline Presence of higher brain dysfunction & $0.693(0.425,1.130)$ & 0.142 & $0.694(0.418,1.154)$ & 0.159 \\
\hline Average daily drug burden, per 0.1 & $0.931(0.877,0.987)$ & 0.017 & $0.924(0.872,0.979)$ & 0.008 \\
\hline
\end{tabular}

the average daily drug burden is independently associated with the time to achieve the BBS cut-off score. Anticholinergic drugs and sedative drugs are widely prescribed. Previous studies have suggested that the use of these medications induces impairment of physical functions such as gait speed and balance in older patients. ${ }^{17,38)}$ The relationship between physical function and the drug burden of anticholinergics and sedatives observed in our study was consistent with these previous reports (Fig. 2), suggesting that there may be an interaction between drug burden and age groups. Further large-scale studies are required to clarify this interaction.

Factors affecting the average daily drug burden include the number of DBI-contributing medications prescribed and the daily doses. We also examined whether the daily dose was an important factor. Of the 41 patients who took one DBI-contributing drug during hospitalization, 35 patients belonged to the low drug burden group and 6 patients belonged to the high drug burden group. The most frequently prescribed DBI-contributing drugs were levetiracetam (eight patients: five in the low drug burden group and three in the high drug burden group), brotizolam (four patients: all in the low drug burden group), and zolpidem (four patients: all in the low drug burden group). Regarding levetiracetam, the daily dose was 500 or $1000 \mathrm{mg}$ /day (1000 mg is the minimum daily dose approved by Ministry of Health, Labour and Welfare) in the low drug burden group and $2000 \mathrm{mg} /$ day in the high drug burden group. Additionally, the administration period may also influence the average drug burden. Brotizolam and zolpidem were used short-term in all patients prescribed these drugs. Only one patient in the high drug burden group was prescribed lorazepam throughout hospitalization, although at the minimum daily dose. Although the sample size was small, our results suggest the possibility that the dose may influence the time to achieve the cut-off values of outcome measures.

We found that patient prescriptions were changed during hospitalization (Table 3), suggesting the possibility that the post-cerebrovascular disease conditions (such as poststroke depression, apathy, or dysuria) changed over time because patients in the Japanese convalescent ward were in the subacute stage. Interestingly, benzodiazepine receptor agonists were more frequently prescribed in the high drug burden group than in the low drug burden group. Zolpidem and brotizolam for insomnia were frequently prescribed in our study population. Guidelines for geriatrics $^{7-9)}$ recommend that these medications should be avoided in elderly patients because of the risks of confusion, sedation, and falls. We propose that both the daily dose and the duration of treatment should be considered carefully so as not to delay the recovery of ADL as measured by FIM-M and balance ability as measured by BBS. Healthcare providers need to share patients' information and pay attention to the doses of anticholinergic agents and sedative drugs as well as the number of these drugs being used in rehabilitation hospitals.

There are some limitations to our study. First, we did not retrieve data on the severity of cerebrovascular disease or the type of higher brain dysfunction. According to pervious research, ${ }^{39)}$ hemispatial neglect, apathy, and right hemisphere brain damage influence the effectiveness of rehabilitation. It was difficult to investigate separately the contributions of symptom severity and high drug burden to the recovery of ADL. However, at least, the attending physician-determined 
A

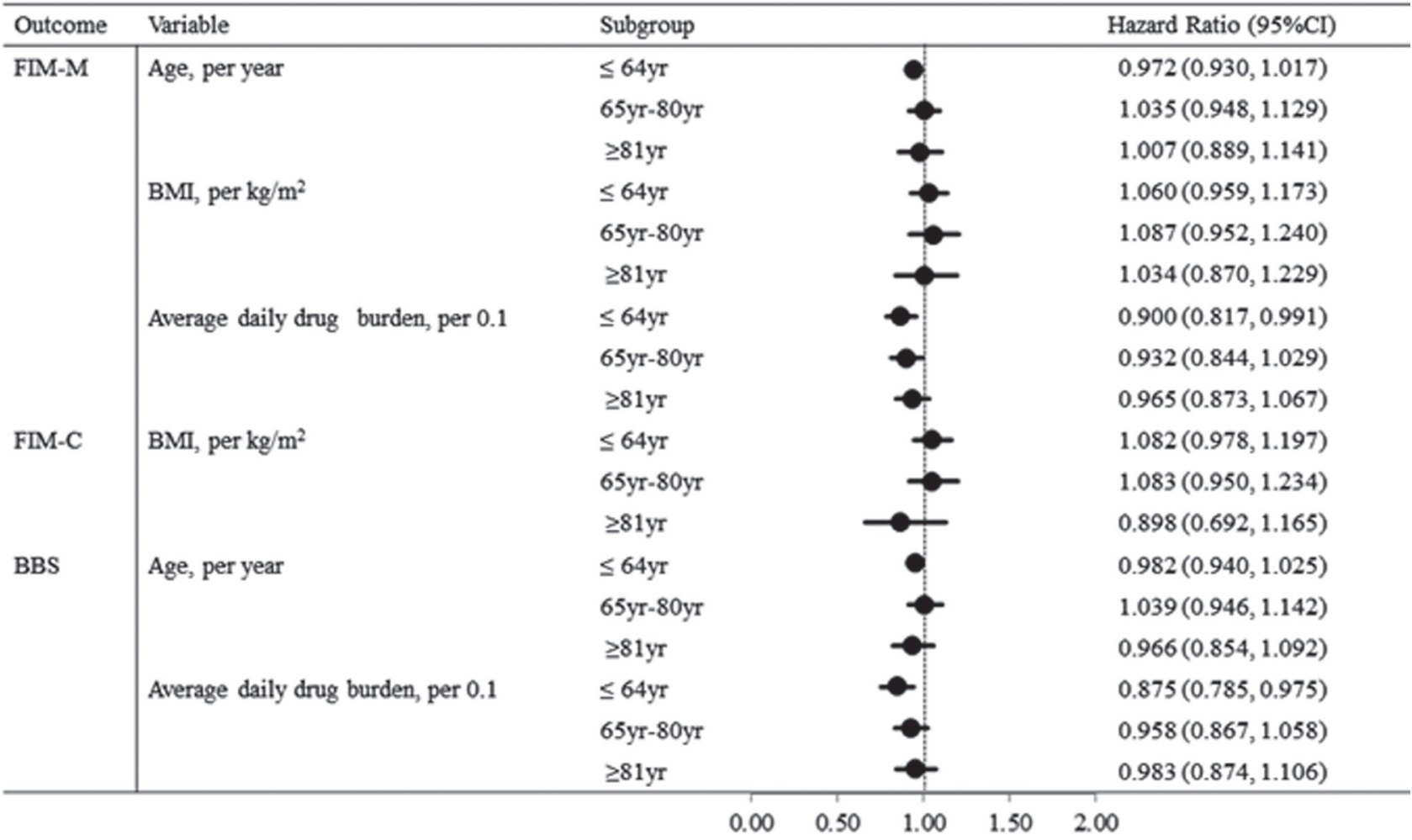

B

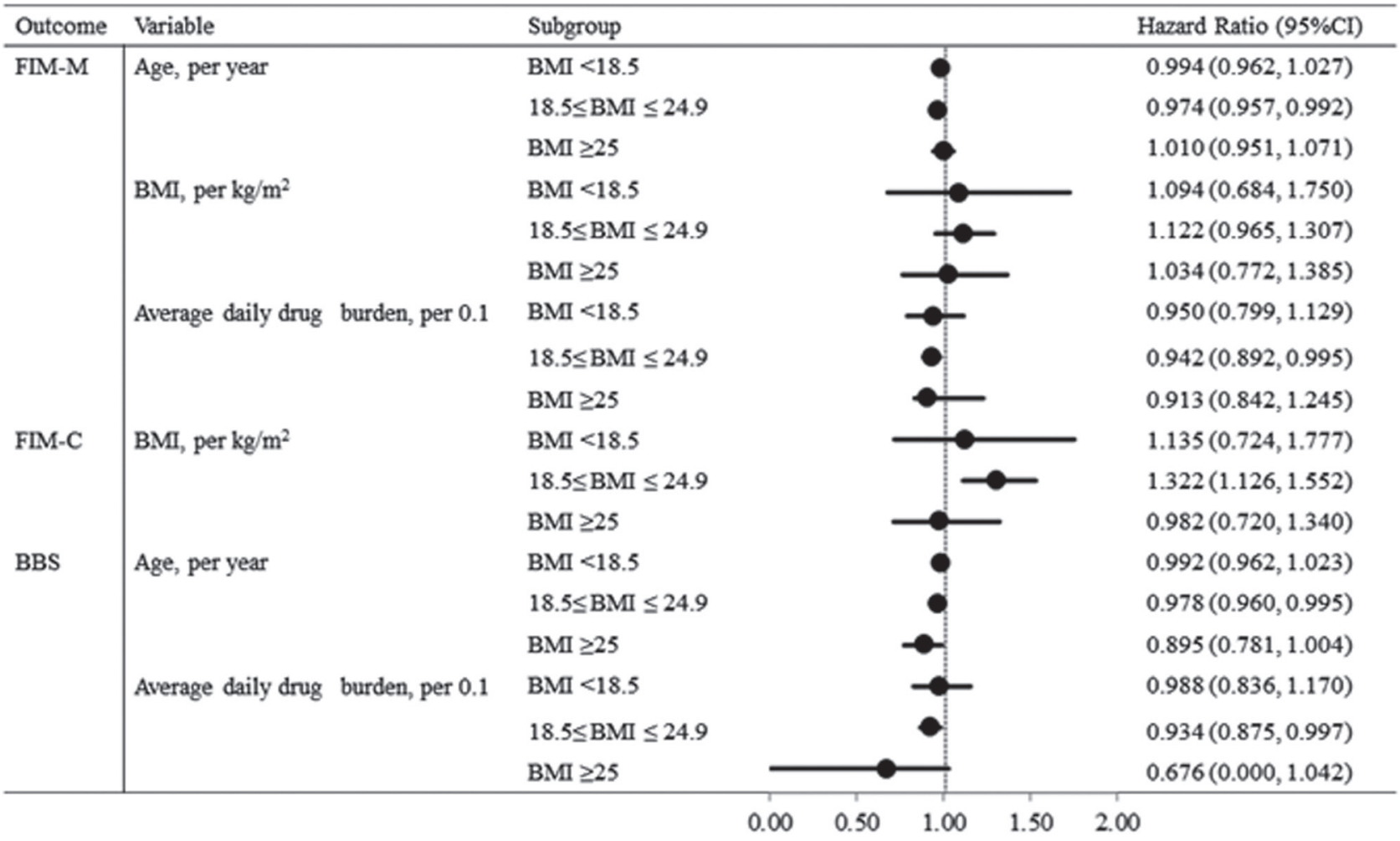

Fig. 2. Subgroup analyses of outcomes by stratifying patients' (A) age and (B) body mass index. BBS, Berg balance scale; BMI, body mass index; CI; confidence interval; FIM-C, Functional Independence Measure-cognitive subscore; FIM-M, Functional Independence Measure--motor subscore. 
median session times of the rehabilitation routine, which might be adjusted according to disease severity, were comparable irrespective of the three drug burden groups (i.e., zero, low, and high drug burden groups), i.e., four sessions for physical therapy, three sessions for occupational therapy, and two sessions for speech therapy. In our study population, the average number of rehabilitation sessions was 8.3 sessions per day. Second, we could not evaluate the impact of drug burden on the recovery of walking ability in severely impaired patients who were unable to undergo or complete a 10MWT during hospitalization. Third, we studied the effect of anticholinergic and sedative drugs together and did not analyze their effects separately. Fourth, the study was retrospective. Finally, the sample size was limited because the Nerima Ken-ikukai Hospital was established in April 2017. Further prospective research with a larger sample size is needed to confirm whether drug burden with anticholinergic and sedative agents influences the recovery of ADL or physical function.

\section{CONCLUSION}

Our descriptive study conducted in a rehabilitation hospital revealed that, in addition to age, the average daily drug burden of anticholinergics/sedatives was independently associated with the time to recovery of FIM-M and BBS. Therefore, both the daily dose and dosing duration of anticholinergic/sedative drugs should be considered carefully to avoid delaying the recovery of ADL and balance ability.

\section{ACKNOWLEDGMENTS}

We would like to thank Teresa Nakatani for English language editing. We would also like to thank Kenji Ito, Yuta Sato, and Soji Tanaka for advice on the outcome measures.

\section{CONFLICTS OF INTEREST}

The authors declare no conflicts of interest.

\section{REFERENCES}

1. Seppala LJ, Wermelink AM, de Vries M, Ploegmakers KJ, van de Glind EM, Daams JG, van der Velde N: EUGMS task and Finish group on fall-risk-increasing drugs: a systematic review and meta-analysis: II. Psychotropics. J Am Med Dir Assoc 2018;19:371.e311-371. e317.
2. Ruxton K, Woodman RJ, Mangoni AA: Drugs with anticholinergic effects and cognitive impairment, falls and all-cause mortality in older adults: a systematic review and meta-analysis. Br J Clin Pharmacol 2015;80:209220. DOI:10.1111/bcp.12617, PMID:25735839

3. Gray SL, Anderson ML, Dublin S, Hanlon JT, Hubbard R, Walker R, Yu O, Crane PK, Larson EB: Cumulative use of strong anticholinergics and incident dementia: a prospective cohort study. JAMA Intern Med 2015;175:401-407. DOI:10.1001/jamainternmed.2014.7663, PMID:25621434

4. Yu NW, Chen PJ, Tsai HJ, Huang CW, Chiu YW, Tsay WI, Hsu J, Chang CM: Association of benzodiazepine and Z-drug use with the risk of hospitalisation for fall-related injuries among older people: a nationwide nested case-control study in Taiwan. BMC Geriatr 2017;17:140. DOI:10.1186/s12877-12017-10530-12874.

5. Gray SL, Dublin S, Yu O, Walker R, Anderson M, Hubbard RA, Crane PK, Larson EB: Benzodiazepine use and risk of incident dementia or cognitive decline: prospective population based study. BMJ 2016;352:i90. DOI:10.1136/bmj.i90, PMID:26837813

6. He Q, Chen X, Wu T, Li L, Fei X: Risk of dementia in long-term benzodiazepine users: evidence from a meta-analysis of observational studies. J Clin Neurol 2019;15:9-19. DOI:10.3988/jen.2019.15.1.9, PMID:30375757

7. By the American Geriatrics Society 2015 Beers Criteria Update Expert Panel: American Geriatrics Society 2015 Updated Beers Criteria for potentially inappropriate dedication use in older adults. J Am Geriatr Soc 2015;63:2227-2246.

8. O’Mahony D, O'Sullivan D, Byrne S, O'Connor MN, Ryan C, Gallagher P: STOPP/START criteria for potentially inappropriate prescribing in older people: version 2. Age Ageing 2014;44:213-218. DOI:10.1093/ ageing/afu145, PMID:25324330

9. The Japan Geriatric Society. Guidelines for Medical Treatment and its Safety in the Elderly 2015 [in Japanese]. Medical View, Tokyo, 2015; pp. 26-31.

10. Skinner BW, Johnston EV, Saum LM: Benzodiazepine initiation and dose escalation. Ann Pharmacother 2017;51:281-285. DOI:10.1177/1060028016682530, PMID:27895235 
11. Woolcott JC, Richardson KJ, Wiens MO, Patel B, Marin J, Khan KM, Marra CA: Meta-analysis of the impact of 9 medication classes on falls in elderly persons. Arch Intern Med 2009;169:1952-1960. DOI:10.1001/archinternmed.2009.357, PMID:19933955

12. Collamati A, Martone AM, Poscia A, Brandi V, Celi M, Marzetti E, Cherubini A, Landi F: Anticholinergic drugs and negative outcomes in the older population: from biological plausibility to clinical evidence. Aging Clin Exp Res 2016;28:25-35. DOI:10.1007/s40520-0150359-7, PMID:25930085

13. Ogawa Y, Sakoh M, Mihara K, Ogawa R, Echizen $\mathrm{H}$ : Factors influencing the number of drugs among elderly patients hospitalized in a rehabilitation ward [in Japanese]. Iryo Yakugaku Jpn J Pharm Health Care Sci 2016;42:56-62. DOI:10.5649/jjphcs.42.56

14. Hilmer SN, Mager DE, Simonsick EM, Cao Y, Ling SM, Windham BG, Harris TB, Hanlon JT, Rubin SM, Shorr RI, Bauer DC, Abernethy DR: A drug burden index to define the functional burden of medications in older people. Arch Intern Med 2007;167:781-787. DOI:10.1001/archinte.167.8.781, PMID:17452540

15. Wouters H, van der Meer H, Taxis K: Quantification of anticholinergic and sedative drug load with the drug burden index: a review of outcomes and methodological quality of studies. Eur J Clin Pharmacol 2017;73:257-266.

DOI:10.1007/s00228-016-2162-6, PMID:27909739

16. Wilson NM, Hilmer SN, March LM, Cameron ID, Lord SR, Seibel MJ, Mason RS, Chen JS, Cumming RG, Sambrook PN: Associations between drug burden index and falls in older people in residential aged care. J Am Geriatr Soc 2011;59:875-880. DOI:10.1111/j.15325415.2011.03386.x, PMID:21539525

17. Lowry E, Woodman RJ, Soiza RL, Hilmer SN, Mangoni AA: Drug burden index, physical function, and adverse outcomes in older hospitalized patients. J Clin Pharmacol 2012;52:1584-1591. DOI:10.1177/0091270011421489, PMID:22167569

18. Hilmer SN, Mager DE, Simonsick EM, Ling SM, Windham BG, Harris TB, Shorr RI, Bauer DC, Abernethy DR, Health ABC Study: Drug burden index score and functional decline in older people. Am J Med 2009;122:1142-1149.e11492. DOI:10.1016/j.amjmed.2009.02.021, PMID:19958893
19. Miyai I, Sonoda S, Nagai S, Takayama Y, Inoue Y, Kakehi A, Kurihara M, Ishikawa M: Results of new policies for inpatient rehabilitation coverage in Japan. Neurorehabil Neural Repair 2011;25:540-547. DOI:10.1177/1545968311402696, PMID:21451116

20. Data Management Service of the Uniform Data System for Medical Rehabilitation and the Center for Functional Assessment Research: Guide for Use of the Uniform Data Set for Medical Rehabilitation, version 3.1. State University of New York at Buffalo, Buffalo, 1990.

21. Lexell J, Flansbjer UB, Holmbäck AM, Downham D, Patten C: Reliability of gait performance tests in men and women with hemiparesis after stroke. J Rehabil Med 2005;37:75-82. DOI:10.1080/16501970410017215, PMID:15788341

22. Tilson J, Sullivan KJ, Cen SY, Rose DK, Koradia CH, Azen SP, Duncan PW, Locomotor Experience Applied Post Stroke (LEAPS) Investigative Team: Meaningful gait speed improvement during the first 60 days poststroke: minimal clinically important difference. Phys Ther 2010;90:196-208. DOI:10.2522/ptj.20090079, PMID:20022995

23. Salter K, Campbell N, Richardson M, Mehta S, Jutai J, Zettler L, Moses M, McClure A, Mays R, Foley N, Teasell R: The Evidence-Based Review of Stroke Rehabilitation. Chapter 20: Outcome Measures in Stroke Rehabilitation. Canadian Partnership for Stroke Recovery. 2013. http://www.ebrsr.com/evidencereview/20-outcome-measures-stroke-rehabilitation. Accessed 2 December 2019.

24. Hamaoka K, Maeda R, Okabayashi A, Sugimoto A, Yamakawa T, Yamanaka S, Hashimoto T, Yoshimoto Y: Functional independence measure reference values for the discharge to home of stroke patients [in Japanese]. Rigakuryouhoukagaku 2014;29:933-937.

25. Perry J, Garrett M, Gronley JK, Mulroy SJ: Classification of walking handicap in the stroke population. Stroke 1995;26:982-989. DOI:10.1161/01.STR.26.6.982, PMID:7762050

26. Berg KO, Wood-Dauphinee SL, Williams JI, Maki B: Measuring balance in the elderly: validation of an instrument. Can J Public Health 1992;83(Suppl 2):S7S11. PMID:1468055

27. Rudolph JL, Salow MJ, Angelini MC, McGlinchey RE: The anticholinergic risk scale and anticholinergic adverse effects in older persons. Arch Intern Med 2008;168:508-513. DOI:10.1001/archinternmed.2007.106, PMID:18332297 
28. Boustani M, Campbell N, Munger S, Maidment I, Fox C: Impact of anticholinergics on the aging brain: a review and practical application. Aging Health 2008;4:311-320. DOI:10.2217/1745509X.4.3.311

29. Carnahan RM, Lund BC, Perry PJ, Pollock BG, Culp KR: The Anticholinergic Drug Scale as a measure of drug-related anticholinergic burden: associations with serum anticholinergic activity. J Clin Pharmacol 2006;46:1481-1486. DOI:10.1177/0091270006292126, PMID:17101747

30. Hsieh FY, Lavori PW: Sample-size calculations for the Cox proportional hazards regression model with nonbinary covariates. Control Clin Trials 2000;21:552-560. DOI:10.1016/S0197-2456(00)00104-5, PMID:11146149

31. Sato R, Arai Y, Abe Y, Takayama M, Urushihara H: The drug burden of anticholinergics and sedatives and influence on outcomes in the community-living oldest old: The Tokyo Oldest Old survey on Total Health (TOOTH) survey [in Japanese]. Nippon Ronen Igakkai Zasshi 2017;54:403-416. DOI:10.3143/geriatrics.54.403, PMID:28855465

32. Yoshimura Y, Wakabayashi H, Bise T, Nagano F, Shimazu S, Shiraishi A, Yamaga M, Koga H: Sarcopenia is associated with worse recovery of physical function and dysphagia and a lower rate of home discharge in Japanese hospitalized adults undergoing convalescent rehabilitation. Nutrition 2019;61:111-118. DOI:10.1016/j.nut.2018.11.005, PMID:30710883

33. Kalichman L, Alperovitch-Najenson D, Treger I: The impact of patient's weight on post-stroke rehabilitation. Disabil Rehabil 2016;38:1684-1690. DOI:10.3109/0963 8288.2015.1107640, PMID:27248186
34. Richardson K, Fox C, Maidment I, Steel N, Loke YK, Arthur A, Myint PK, Grossi CM, Mattishent K, Bennett K, Campbell NL, Boustani M, Robinson L, Brayne C, Matthews FE, Savva GM: Anticholinergic drugs and risk of dementia: case-control study. BMJ 2018;361:k1315. DOI:10.1136/bmj.k1315.

35. Park KR, Kim KB, Baek YH, Sung HG, Park JT, Lee EK, Shin JY: Signal detection of benzodiazepine use and risk of dementia: sequence symmetry analysis using South Korean national healthcare database. Int J Clin Pharm 2018;40:1568-1576. DOI:10.1007/s11096018-0739-0, PMID:30367378

36. Yeo SH, Lim ZI, Mao J, Yau WP: Effects of central nervous system drugs on recovery after stroke: a systematic review and meta-analysis of randomized controlled trials. Clin Drug Investig 2017;37:901-928. DOI:10.1007/s40261-017-0558-4, PMID:28756557

37. Gu SC, Wang CD: Early selective serotonin reuptake inhibitors for recovery after stroke: a meta-analysis and trial sequential analysis. J Stroke Cerebrovasc Dis 2018;27:1178-1189. DOI:10.1016/j.jstrokecerebrovasdis.2017.11.031, PMID:29276014

38. Nurminen J, Puustinen J, Lähteenmäki R, Vahlberg T, Lyles A, Partinen M, Räihä I, Neuvonen PJ, Kivelä SL: Handgrip strength and balance in older adults following withdrawal from long-term use of temazepam, zopiclone, or zolpidem as hypnotics. BMC Geriatr 2014;14:121. DOI:10.1186/1471-2318-1114-1121

39. Kanaya K, Katsunuma H, Tabata M, Akiba Y, Umahara T, Takasaki M: [Deterrent factors in rehabilitation training following cerebral vascular disease-comparison of elderly and non-elderly patients] [in Japanese]. Nippon Ronen Igakkai Zasshi 1997;34:639-645. DOI:10.3143/geriatrics.34.639, PMID:9396319 